\title{
AVALIAÇÃO, PURIFICAÇÃO E CARACTERIZAÇÃO DE UM BIOPOLİMERO MUCOADESIVO E SUA UTILIZAÇÃO EM PRODUTOS FARMACÊUTICOS
}

\begin{abstract}
Francisco B. T. Pessine (PQ), Letícia P. Marques (PG), Juciane de P. André (IC)
\section{Resumo}

Este projeto tem como objetivo a caracterização de amostras de quitosana e sua utilização na produção de micropartículas para a encapsulação de fármaco. Partindo de amostras de quitosana bruta, realizaram-se reações de desacetilação para purificar o material. A fim de analisar a qualidade do processo, foram realizadas medidas espectroscópicas na região do infravermelho, ressonância magnética nuclear de ${ }^{13} \mathrm{C}$, calorimetria diferencial de varredura e análise termogravimétrica. Após obtenção de micropartículas com o perfil adequado, prosseguiu-se com a encapsulação do fármaco 5-fluoracil (5 - FU), um antineoplásico utilizado no tratamento de muitos tipos de cânceres ${ }^{2}$.
\end{abstract}

Palavras Chave: quitosana, micropartículas, 5-fluoracil

\section{Introducão}

Quitosana, um biopolímero proveniente da desacetilação da quitina presente na carapaça de crustáceos, possui propriedades químicas e biológicas importantes para várias aplicações tecnológicas ${ }^{1}$.

Quando comparada a excipientes farmacêuticos formadores de gel tradicionais, a quitosana tem demonstrado propriedades superiores, com maior flexibilidade, somada à característica de formação de biofilme para recobrimento e isenção de toxicidade.

Este projeto destinou-se à caracterização e produção de micropartículas desse biopolímero , utilizando tripolifosfato de sódio $\left(\mathrm{Na}_{3} \mathrm{PO}_{4}\right)$, TPP, como agente reticulante. As micropartículas foram produzidas com a finalidade de estudar a viabilidade do seu uso na encapsulação de fármacos.

\section{Resultados e Discussão}

Após a purificação (desacetilação) da quitosana, cujo rendimento foi de $78,2 \%$, realizaram-se medidas espectroscópicas de absorção na região do infravermelho. Além disso, foram realizadas análises de RMN ${ }^{13} \mathrm{C}$, DSC e TGA

A partir de valores de absorbância obtidos nas análises de infravermelho e, utilizando equações descritas na literatura ${ }^{3}$, foi possível determinar 0 grau de desacetilação da quitosana purificada. Obteve-se o valor de $82,5 \%$.

$\mathrm{Na}$ produção das micropartículas, o meio foi tamponado e mantido com pH 4,5. Realizou-se um planejamento fatorial para determinar a melhor formulação no que se refere à homogeneidade na distribuição de tamanhos e estabilidade da emulsão.
Após a obtenção do perfil descrito, o qual foi monitorado por difração a laser, realizou-se a encapsulação do 5 - fluoracil. Os próximos experimentos serão destinados ao monitoramento do comportamento da formulação com relação à estabilidade do fármaco nas micropartículas. Além disso, pretende-se monitorar o perfil de libração do 5 - fluoracil. Para isso, serão empregadas medidas de absorbância na região do UV - VIS.

\section{Conclusões}

A partir dos experimentos realizados até agora, pode-se concluir que o processo de purificação da quitosana apresenta resultados satisfatórios, tendo em vista o alto rendimento de $78,2 \%$. Constatou-se, também, que a melhor condição do planejamento para a produção das micropartículas é a que parte da solução de quitosana a $0,5 \%$ e TPP a $10 \%$.

\section{Agradecimentos}

Instituição de fomento: Pró - reitoria de pesquisa (PRP) - Unicamp/ Programa de iniciação em desenvolvimento tecnológico e inovação.

Empresa incubada: ANSPharma

\footnotetext{
${ }^{1}$ Yamamura, M. A Química das Quitosanas. Chemkeys, 2009

${ }^{2}$ Matuo, R. Avaliação da atividade citotóxica de 5 - fluorouracil e seu metabólito FdUMP e os sistemas de reparo envolvidos. 2008. 115f. Dissertação (Mestrado) - Instituto de Biociências, Universidade Federal do Rio Grande do Sul, Rio Grande do Sul. 2008.

${ }^{3}$ Kasaai, M. R. A review of several reported procedures to determine the degree of $\mathrm{N}$ - acetylation for chitin and chitosan using infrared spectroscopy. Carbohydrate Polymers 71, pp 497 - 508, 2008
} 